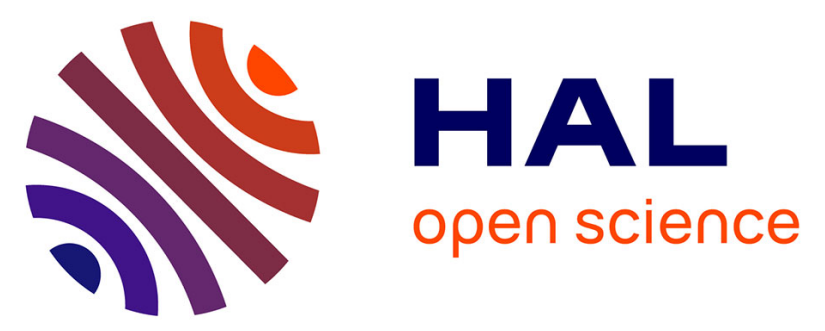

\title{
A New Orbito-Zygomatic Complex Reconstruction Technique Using Computer-Aided Design and Manufacturing-Assisted Harvest of Autologous Calvarial Bone in Cases of Orbito-Zygomatic Benign Tumor
}

Romain Nicot, Matthias Schlund, Camille Sentucq, Gwénaël Raoul

\section{- To cite this version:}

Romain Nicot, Matthias Schlund, Camille Sentucq, Gwénaël Raoul. A New Orbito-Zygomatic Complex Reconstruction Technique Using Computer-Aided Design and Manufacturing-Assisted Harvest of Autologous Calvarial Bone in Cases of Orbito-Zygomatic Benign Tumor. Journal of Oral and Maxillofacial Surgery, 2019, 77, pp.1082 - 1091. 10.1016/j.joms.2018.12.024 . hal-03486860

\author{
HAL Id: hal-03486860 \\ https://hal.science/hal-03486860
}

Submitted on 20 Dec 2021

HAL is a multi-disciplinary open access archive for the deposit and dissemination of scientific research documents, whether they are published or not. The documents may come from teaching and research institutions in France or abroad, or from public or private research centers.
L'archive ouverte pluridisciplinaire $\mathbf{H A L}$, est destinée au dépôt et à la diffusion de documents scientifiques de niveau recherche, publiés ou non, émanant des établissements d'enseignement et de recherche français ou étrangers, des laboratoires publics ou privés.

\section{(ㄷ)(1) $\$$}

Distributed under a Creative Commons Attribution - NonCommerciall 4.0 International 


\title{
A New Orbito-Zygomatic Complex Reconstruction Technique Using Computer-Aided Design and Manufacturing-Assisted Harvest of Autologous Calvarial Bone in Cases of Orbito-Zygomatic Benign Tumor
}

\author{
Romain Nicot, MD, MSc, ${ }^{*}$ Matthias Schlund, MD,$\dagger$ \\ Camille Sentucq, $\ddagger$ and Gwénä̈l Raoul, MD, PbD $\S$
}

\begin{abstract}
The orbito-zygomatic complex (OZC) includes several key structures, and its destruction leads to the impairment of functional activities such as nutrition, communication, nasal support, and vision. Management of benign tumors of the OZC is therefore a surgical challenge because of the necessity for reconstruction of these elements. Autogenous bone is considered the gold standard for reconstruction. Nevertheless, there is difficulty related to the complex anatomy and distorted skeletal anatomic landmarks, which require precise work in the case of bone grafts. The aim of this report is to propose a new reconstruction technique consisting of OZC reconstruction with computer-aided design and manufacturing of autologous calvarial bone. Three cases are presented. After performing tumor resection using computeraided design and manufacturing cutting guides, we used a piezotome to perform osteotomies and preserve the periosteum and sinus mucosa. The SinpliciTi system (Materialise, Châtillon, France) allowed us to make cutting guides and a 3-dimensional surgical plan of the shapes and ideal positions of the calvarial bony plates for the $\mathrm{OZC}$ reconstruction. Calvarial osteotomies were performed using a piezotome through the polyamide calvarial cutting guide to obtain the shapes designed beforehand. Once the samples were collected, the shapes could be assembled ex vivo and then put in place through a minimally invasive approach. We discuss the advantages and limitations of our reconstruction method and its place in the management of OZC reconstruction.
\end{abstract}

(c) 2018 American Association of Oral and Maxillofacial Surgeons

J Oral Maxillofac Surg 77:1082-1091, 2019

Benign tumors of the orbito-zygomatic complex (OZC) are usually not life-threatening, and treatment options are wide-ranging, from simple observation to surgery. However, extensive bone tumors may threaten key structures, such as the optic nerve, and require complete tumor excision. Bone defects of the face can have dramatic functional, esthetic, and social repercussions. Destruction of the midface leads
*Senior Lecturer, University of Lille; Department of Oral and Maxillofacial Surgery, CHU Lille; and INSERM U1008, Controlled Drug Delivery Systems and Biomaterials, Lille, France.

$\dagger$ Chief Resident, University of Lille, and Department of Oral and Maxillofacial Surgery, CHU Lille, Lille, France.

$\ddagger$ Resident, University of Lille, and Department of Oral and Maxillofacial Surgery, CHU Lille, Lille, France.

$\S$ Professor, University of Lille; Department of Oral and Maxillofacial Surgery, CHU Lille; and INSERM U1008, Controlled Drug Delivery Systems and Biomaterials, Lille, France.

Conflict of Interest Disclosures: None of the authors have any relevant financial relationship(s) with a commercial interest.
Address correspondence and reprint requests to $\mathrm{Dr}$ Nicot: Service de Chirurgie Maxillo Faciale et Stomatologie, Hôpital Roger Salengro, Bd du Prof Emile Laine, 59037 Lille-Cedex, France; e-mail: romain.nicot@gmail.com

Received August 142018

Accepted December 222018

(C) 2018 American Association of Oral and Maxillofacial Surgeons

0278-2391/18/31394-6

https://doi.org/10.1016/i.joms.2018.12.024 


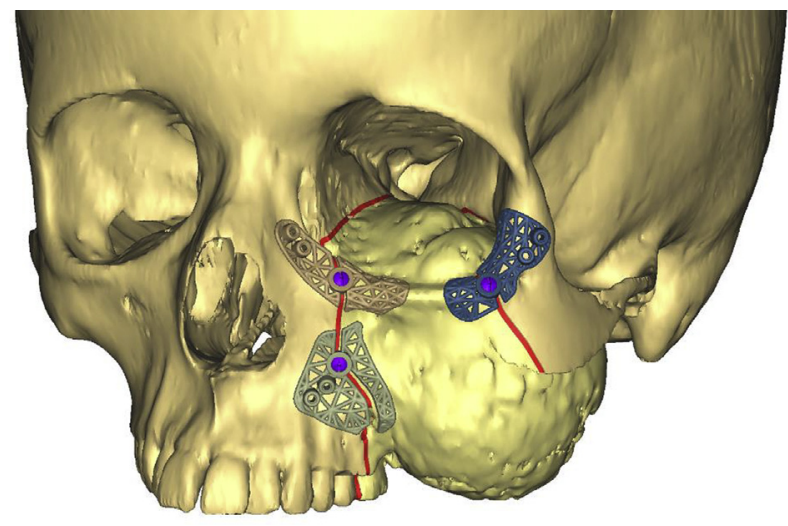

FIGURE 1. Surgical planning of orbito-zygomatic complex excision in 13-year-old patient with fibrous dysplasia.

Nicot et al. Orbito-Zygomatic Complex Reconstruction. J Oral Maxillofac Surg 2019.

to the impairment of key features influencing nutrition, communication, nasal support, vision, and maintenance of oral hygiene. ${ }^{1,2}$ It also results in the destruction of self-esteem with consequences for mental health and a loss of social acceptability.

Reconstruction of the OZC represents a surgical challenge owing to the functional, esthetic, and psychological implications of this area. A variety of techniques and materials are used to fulfill these objectives, making the treatment plan more complex. $^{2,3}$ Several patient-specific implants have been described, consisting of titanium, polyether ether ketone, Medpor (Stryker, Kalamazoo, MI), or

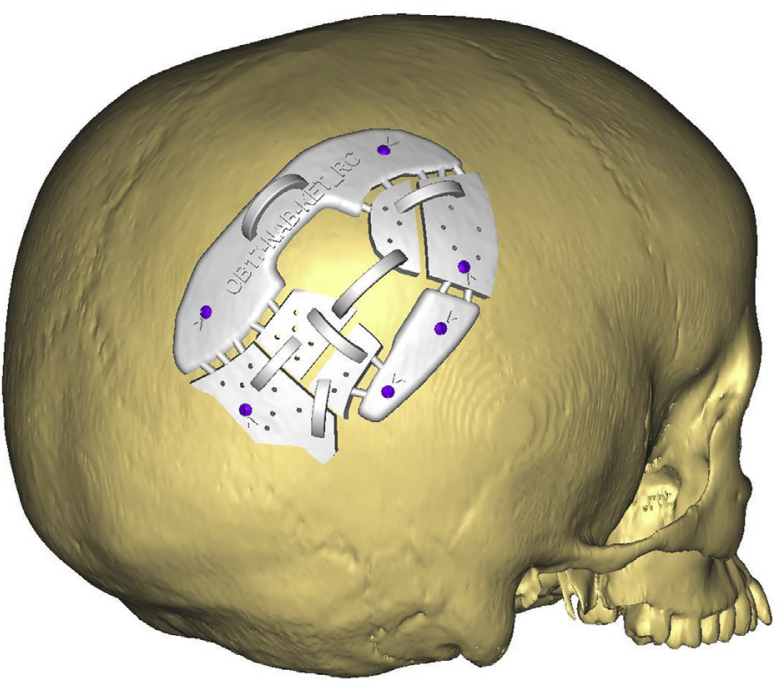

FIGURE 2. Computer-aided design and manufacturing polyamide cutting guide to obtain chosen calvarial bone grafts in 13-year-old patient with fibrous dysplasia. The cutting guide was designed with drill holes that corresponded to the final screw positions on the bone samples.

Nicot et al. Orbito-Zygomatic Complex Reconstruction.J Oral Maxillofac Surg 2019.

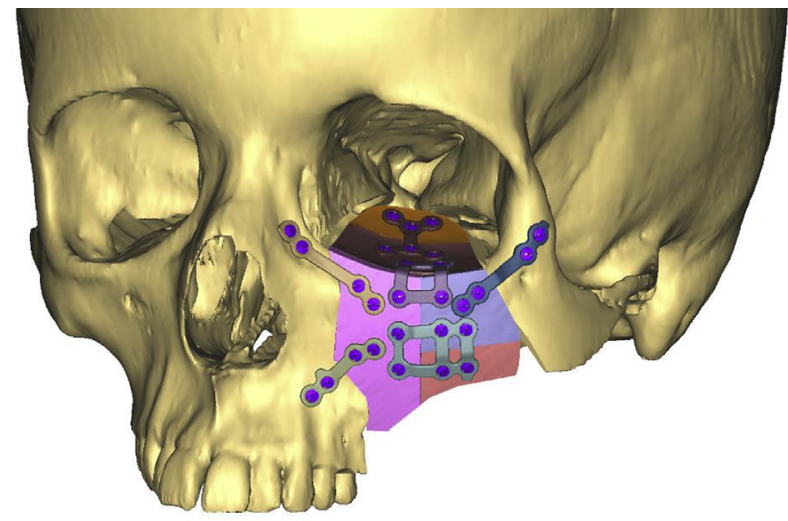

FIGURE 3. Surgical planning of orbito-zygomatic complex reconstruction with calvarial bone grafts in 13-year-old patient with fibrous dysplasia.

Nicot et al. Orbito-Zygomatic Complex Reconstruction. J Oral Maxillofac Surg 2019.

Vitroceramics. Nevertheless, autogenous bone is still considered the gold standard in reconstructive surgery. ${ }^{4}$ On the other hand, obtaining optimum results is difficult given distorted skeletal anatomic landmarks in several cases of benign tumors.

Three-dimensional analysis and planning are powerful tools in craniofacial and reconstructive surgery. They are already used for intraoperative navigation, 3-dimensional printouts of guides, ${ }^{5}$ or patientspecific implants. ${ }^{6}$ They can be used for the reconstitution of missing tissue, repositioning of misplaced tissue, and removal and reshaping of structural elements-or a combination thereof. Computer-assisted preoperative planning by mirroring and intraoperative navigation has improved the procedure of craniofacial reconstruction. There is indeed a general consensus that computer-aided virtual planning allows more predictable results and is therefore becoming

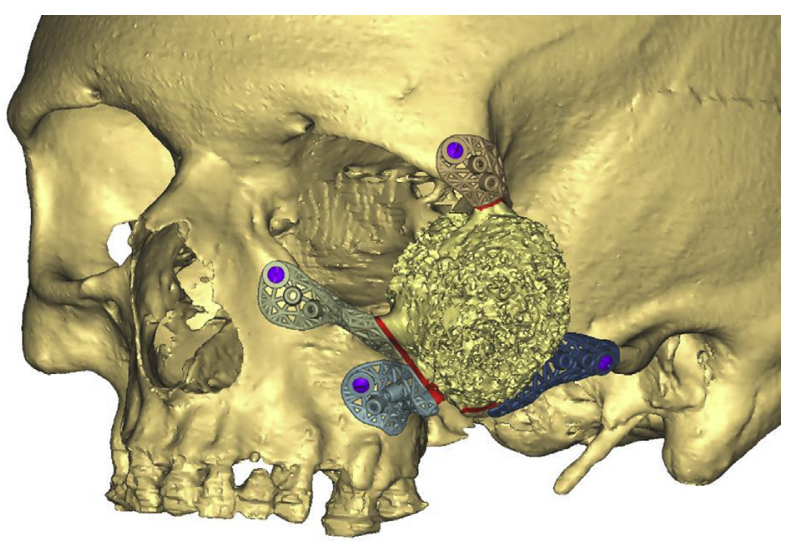

FIGURE 4. Surgical planning of orbito-zygomatic complex excision in 58-year-old woman with osseous cavernous hemangioma.

Nicot et al. Orbito-Zygomatic Complex Reconstruction. J Oral Maxillofac Surg 2019. 


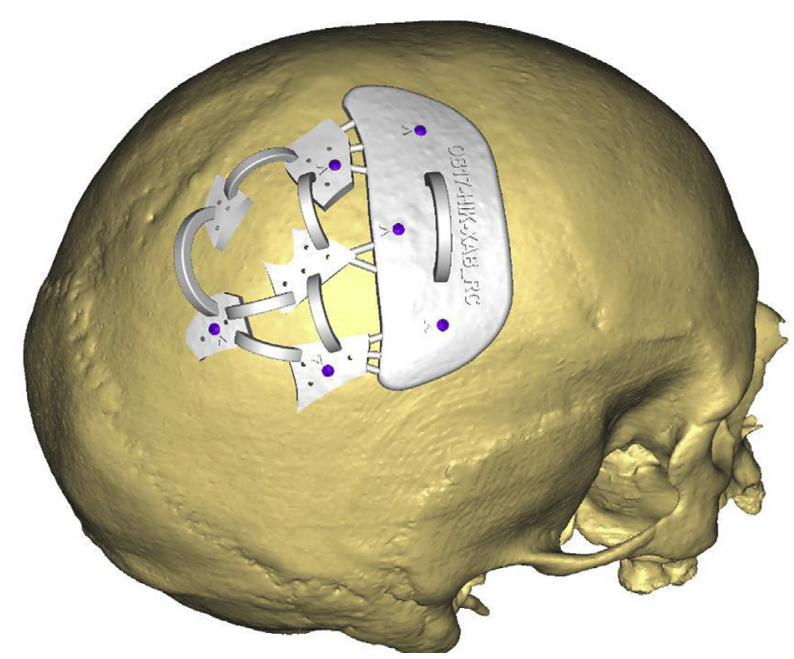

FIGURE 5. Computer-aided design and manufacturing polyamide cutting guide to obtain chosen calvarial bone grafts in 58-year-old woman with osseous cavernous hemangioma. The cutting guide was designed with drill holes that corresponded to the final screw positions on the bone samples.

Nicot et al. Orbito-Zygomatic Complex Reconstruction.J Oral Maxillofac Surg 2019.

indispensable in reconstructive surgery. ${ }^{1,2,5-7}$ The aim of this report is to propose a new reconstruction technique consisting of OZC reconstruction with computer-aided design and manufacturing (CADCAM) of autologous calvarial bone.

\section{Patients and Methods}

We performed a surgical excision and reconstruction technique using autologous bone grafts with a CAD-CAM support. The different surgical plans for OZC reconstruction are presented in Figures 1 to 9, showing fibrous dysplasia in a 13 -year-old patient, an

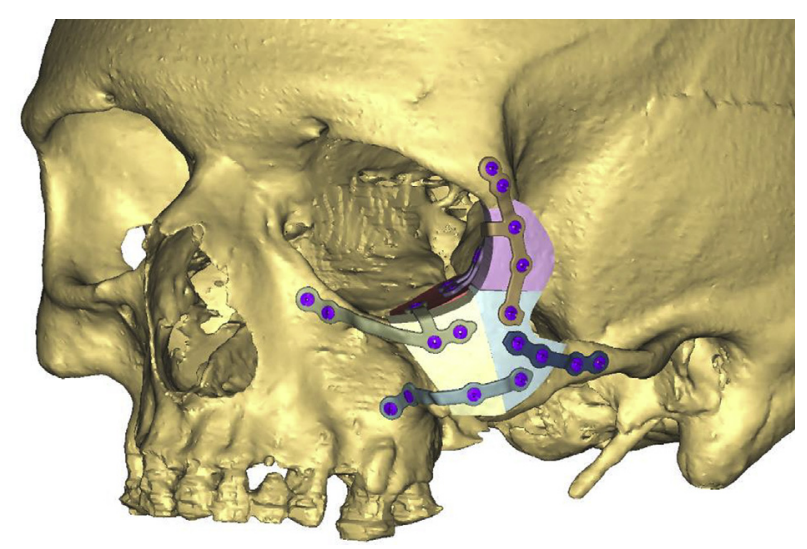

FIGURE 6. Surgical planning of orbito-zygomatic complex reconstruction with calvarial bone grafts in 58-year-old woman with osseous cavernous hemangioma.

Nicot et al. Orbito-Zygomatic Complex Reconstruction.J Oral Maxillofac Surg 2019.

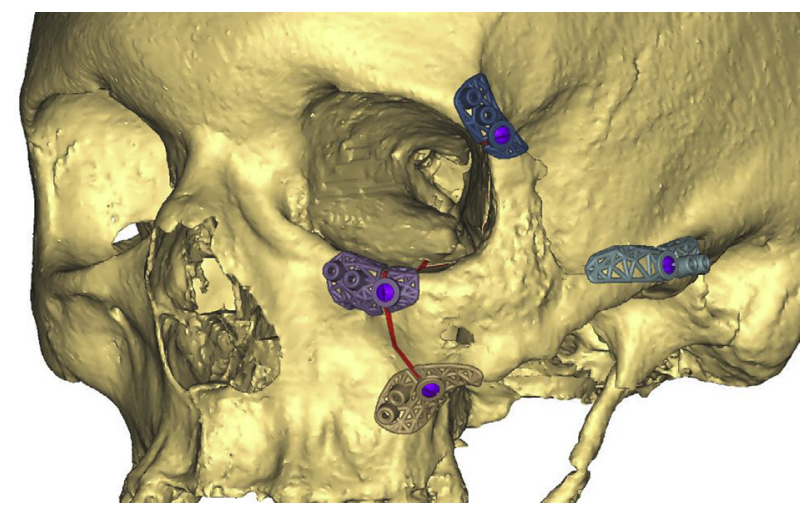

FIGURE 7. Surgical planning of orbito-zygomatic complex excision in 63-year-old woman with basal cell carcinoma with in-depth invasion of zygomatic bone.

Nicot et al. Orbito-Zygomatic Complex Reconstruction. J Oral Maxillofac Surg 2019.

osseous cavernous hemangioma in a 58-year-old woman, and a basal cell carcinoma with in-depth invasion of the zygomatic bone in a 63-year-old woman. French Ethics Committee approval was not required for this research. The study conformed to the provisions of the Declaration of Helsinki.

Surgical resections of these OZC tumors were performed by a minimally invasive approach when possible, using designed titanium cutting guides. The surgical approach consisted of a subciliary approach sometimes supplemented by an intraoral approach or paralateronasal approach, depending on the tumor size and location. Tumor resection was performed using CAD-CAM titanium cutting guides placed on each side of the lesion: infraorbital rim,

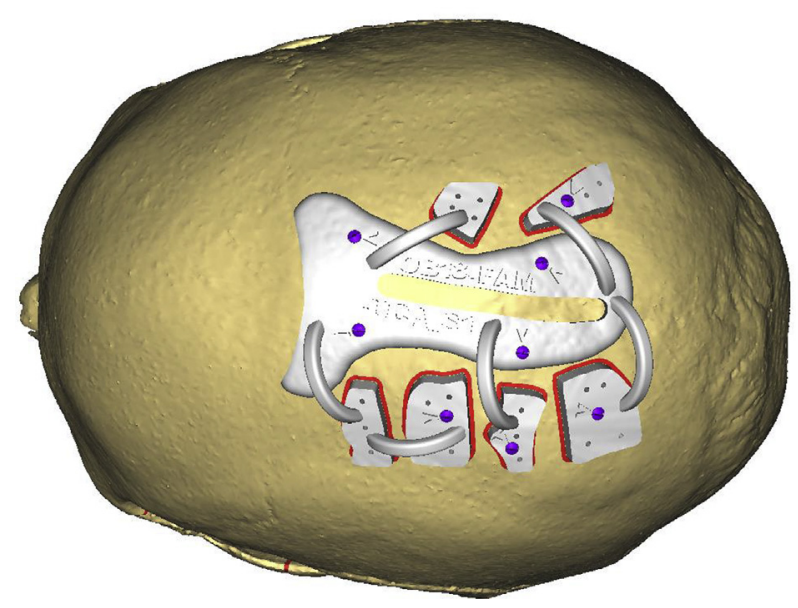

FIGURE 8. Computer-aided design and manufacturing polyamide cutting guide to obtain chosen calvarial bone grafts in 63-year-old woman with basal cell carcinoma with in-depth invasion of zygomatic bone. The cutting guide was designed with drill holes that corresponded to the final screw positions on the bone samples.

Nicot et al. Orbito-Zygomatic Complex Reconstruction.J Oral Maxillofac Surg 2019. 


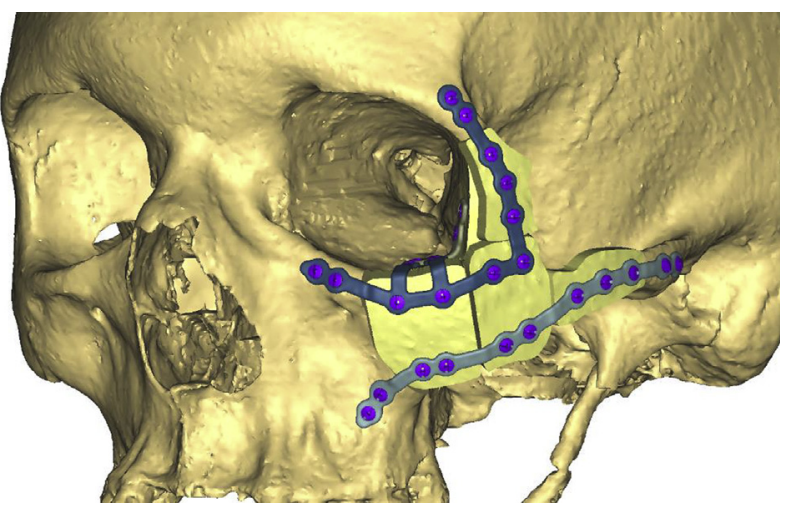

FIGURE 9. Surgical planning of orbito-zygomatic complex reconstruction with calvarial bone grafts in 63-year-old woman with basal cell carcinoma with in-depth invasion of zygomatic bone.

Nicot et al. Orbito-Zygomatic Complex Reconstruction. J Oral Maxillofac Surg 2019.

zygomaticomaxillary buttress, and frontal process and temporal process of zygomatic bone. Holes for the fixation of the titanium miniplates were drilled through the cutting guide (Fig 10). Osteotomies were performed using a piezotome to preserve the periosteum and sinus mucosa. We used the SinpliciTi system (Materialise, Châtillon, France) ${ }^{7}$ to make cutting guides and a 3-dimensional surgical plan of the shapes and ideal positions of the calvarial bony plates for the $\mathrm{OZC}$ reconstruction. The number and shape of bone fragments collected depended on the extent of the reconstruction and the potentially associated orbital floor reconstruction. Osteotomies were performed using a piezotome through the polyamide calvarial cutting guide to obtain the previously designed shape (Fig 11). The bone samples collected were exclusively

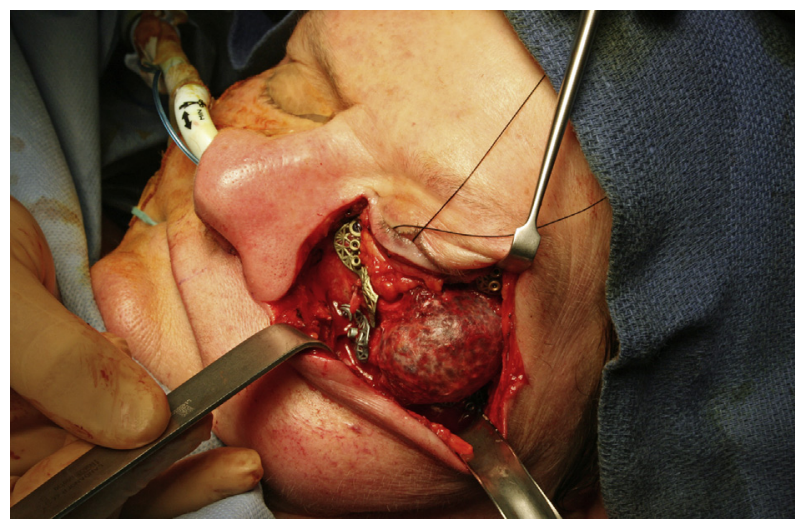

FIGURE 10. Surgical resection of osseous cavernous hemangio$\mathrm{ma}$ in 58-year-old woman using computer-aided design and manufacturing titanium cutting guide placed on each side of lesion: infraorbital rim, zygomaticomaxillary buttress, and frontal process and temporal process of zygomatic bone. Cutting guides included drill holes that corresponded to the final screw positions.

Nicot et al. Orbito-Zygomatic Complex Reconstruction.J Oral Maxillofac Surg 2019. unicortical. Sampling sites were filled with $\beta$ tricalcium phosphate. Cutting guides were designed with drill holes that corresponded to the final screw positions on the bone samples. Once samples were collected, the assembly was created ex vivo following the surgical planning. Each sample had a predefined and singular shape, making it easy to recognize. Therefore, the assembly was performed simply, by screwing the custom-made titanium plates in the predefined holes. The assembly was then put in place in 2 pieces through the minimally invasive approach-the zygomatic body piece and the orbital floor piece-which were then assembled by a titanium miniplate at the infraorbital rim. Designed titanium miniplates were used to achieve stability of the different bone fragments. No complications occurred during the surgical

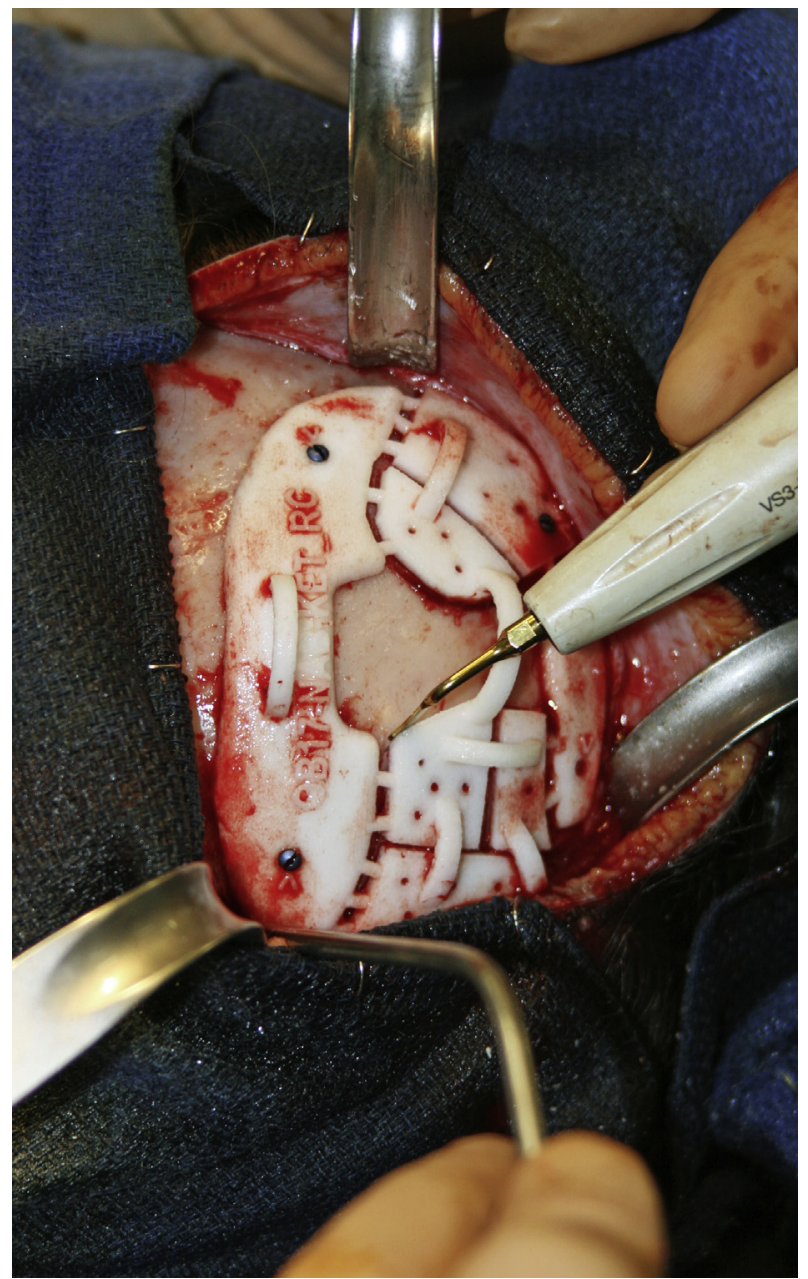

FIGURE 11. Computer-aided design and manufacturing surgical cutting guide used for monocortical calvarial bone graft harvesting in reconstruction of orbito-zygomatic fibrous dysplasia in 13-yearold patient. Harvesting was performed using a piezotome, and donor sites were filled with $\beta$ tricalcium phosphate. Cutting guides included drill holes that corresponded to the final screw positions.

Nicot et al. Orbito-Zygomatic Complex Reconstruction.J Oral Maxillofac Surg 2019. 


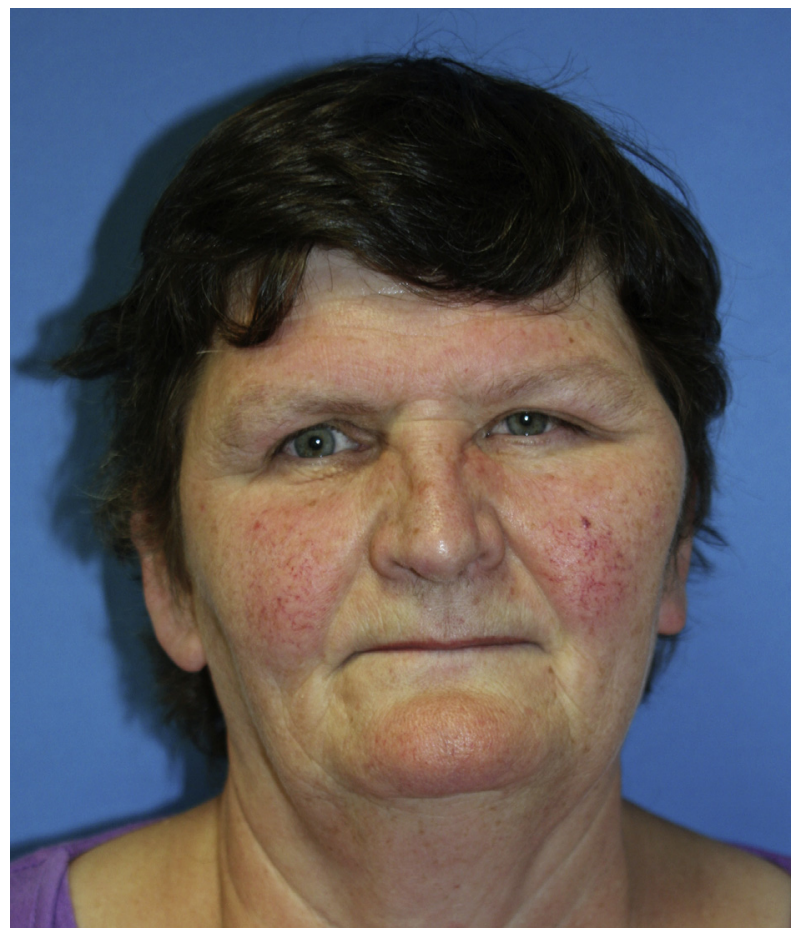

FIGURE 12. Preoperative front view of 58-year-old woman with orbito-zygomatic osseous cavernous hemangioma. The patient had facial asymmetry associated with dystopia. There was no diplopia given the progressive occurrence of the lesion.

Nicot et al. Orbito-Zygomatic Complex Reconstruction.J Oral Maxillofac Surg 2019.

procedures. Clinical (Figs 12-15) and radiologic (Figs 16-21) follow-up showed stability of long-term results.

\section{Discussion}

We present a new technique for reconstruction of the OZC using an autologous calvarial bone graft with a CAD-CAM support. This technique has the

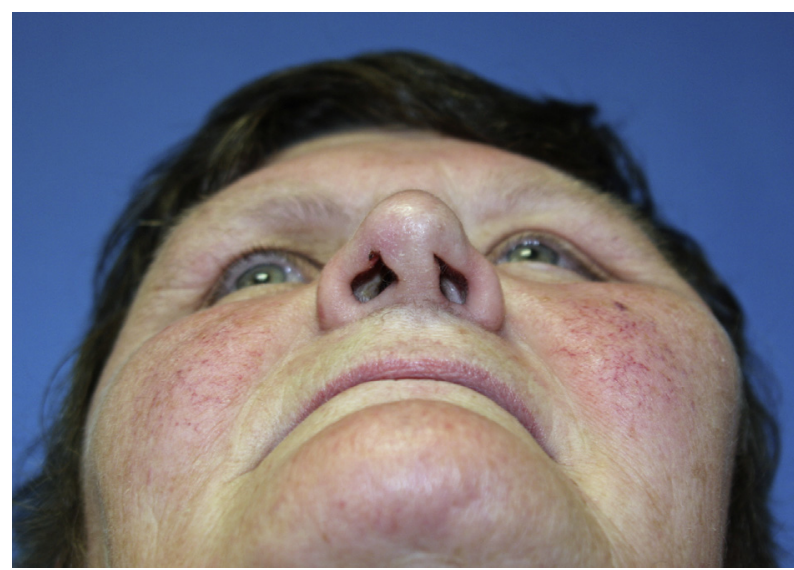

FIGURE 13. Preoperative bottom view of 58-year-old woman with orbito-zygomatic osseous cavernous hemangioma.

Nicot et al. Orbito-Zygomatic Complex Reconstruction. J Oral Maxillofac Surg 2019.

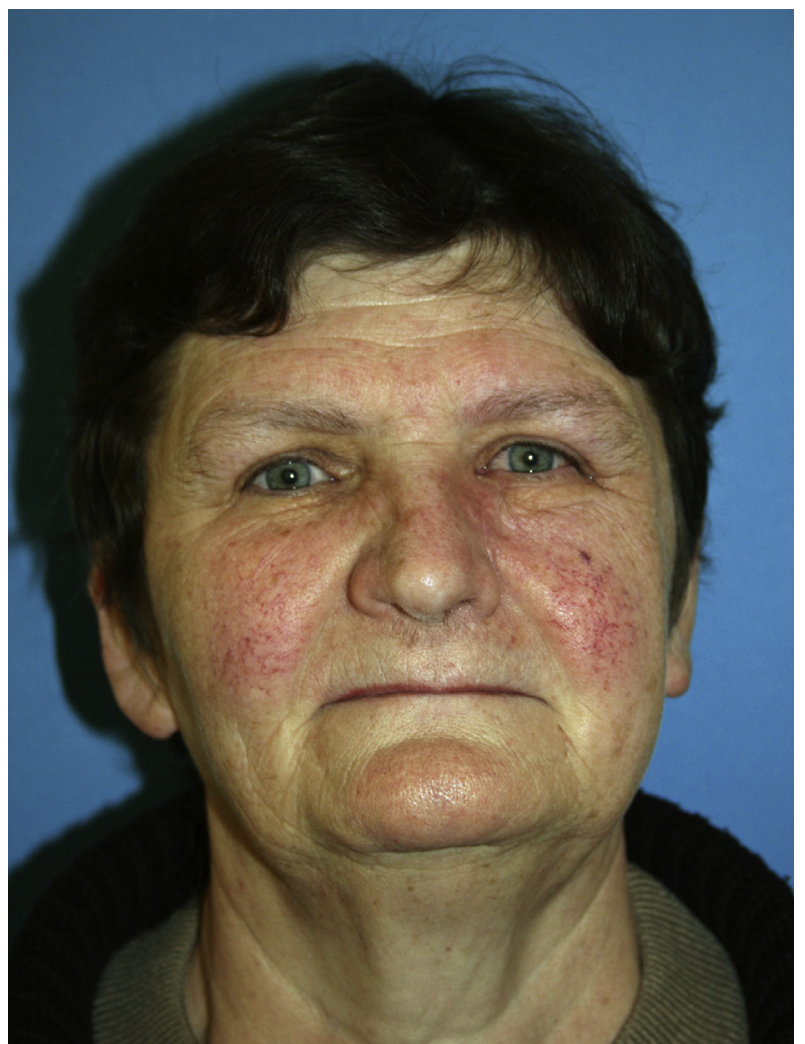

FIGURE 14. Postoperative front view of 58-year-old woman with orbito-zygomatic osseous cavernous hemangioma. We performed surgical excision with cutting guides and orbito-zygomatic reconstruction with calvarial bone grafts using a computer-aided design and manufacturing system. A subciliary approach combined with a paralateronasal approach was used to achieve both the excision and reconstruction parts of the surgical procedure.

Nicot et al. Orbito-Zygomatic Complex Reconstruction.J Oral Maxillofac Surg 2019.

main advantage of using autologous bone implants, which are considered the gold standard for craniofacial reconstruction, owing to their osteogenic,

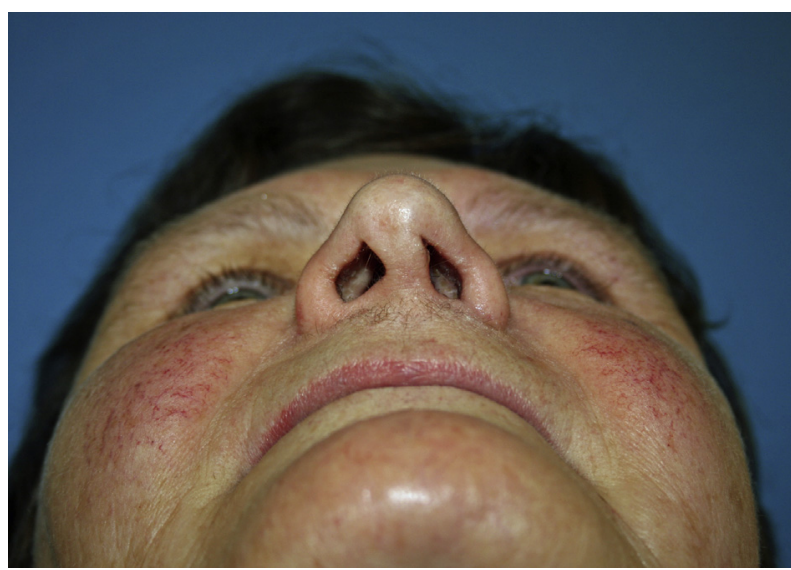

FIGURE 15. Postoperative bottom view of 58-year-old woman with orbito-zygomatic osseous cavernous hemangioma.

Nicot et al. Orbito-Zygomatic Complex Reconstruction. J Oral Maxillofac Surg 2019 


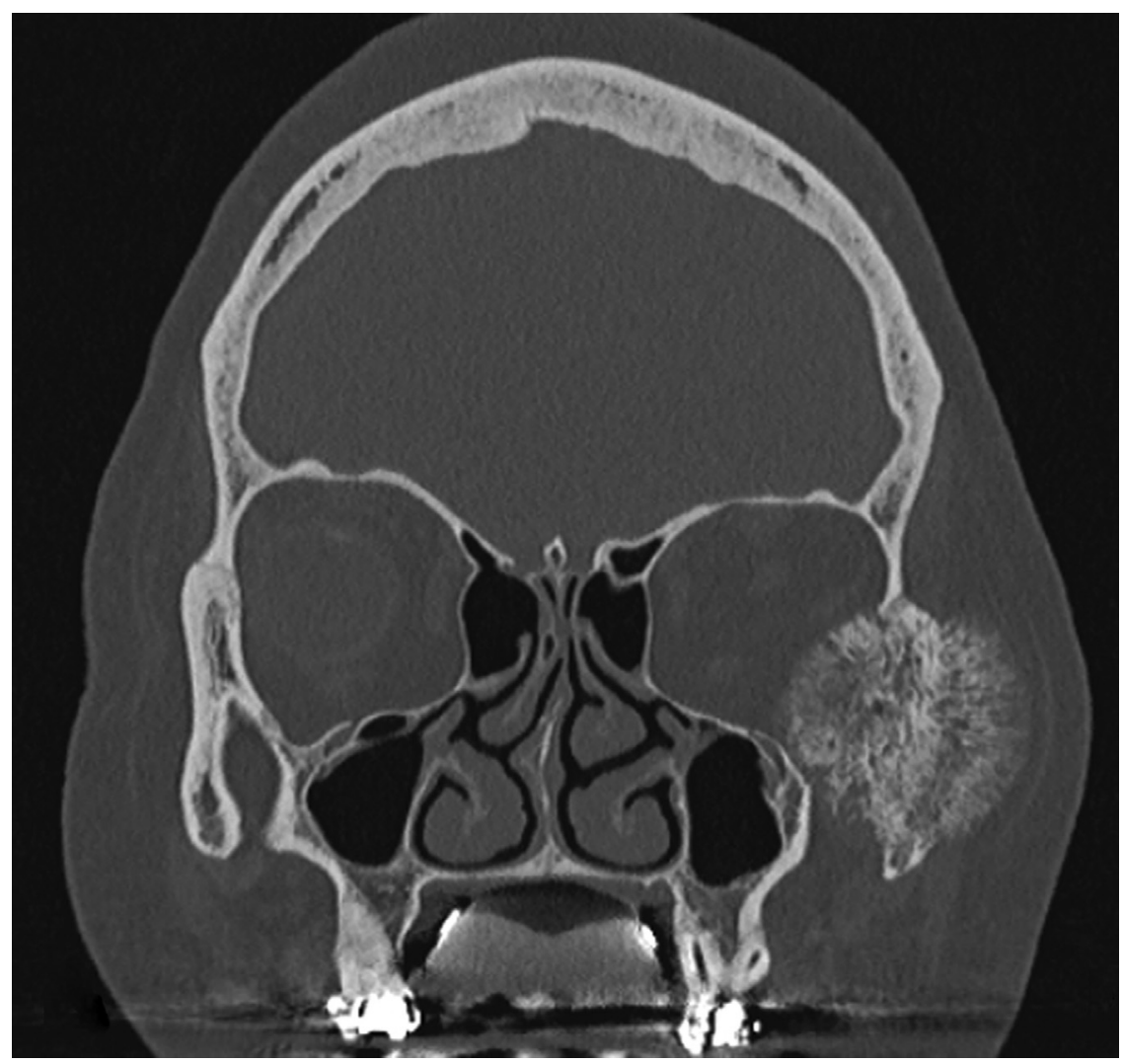

FIGURE 16. Coronal view of preoperative computed tomography scan of 58-year-old woman with orbito-zygomatic osseous cavernous hemangioma. The tumor was responsible for an intraorbital mass effect.

Nicot et al. Orbito-Zygomatic Complex Reconstruction. J Oral Maxillofac Surg 2019.

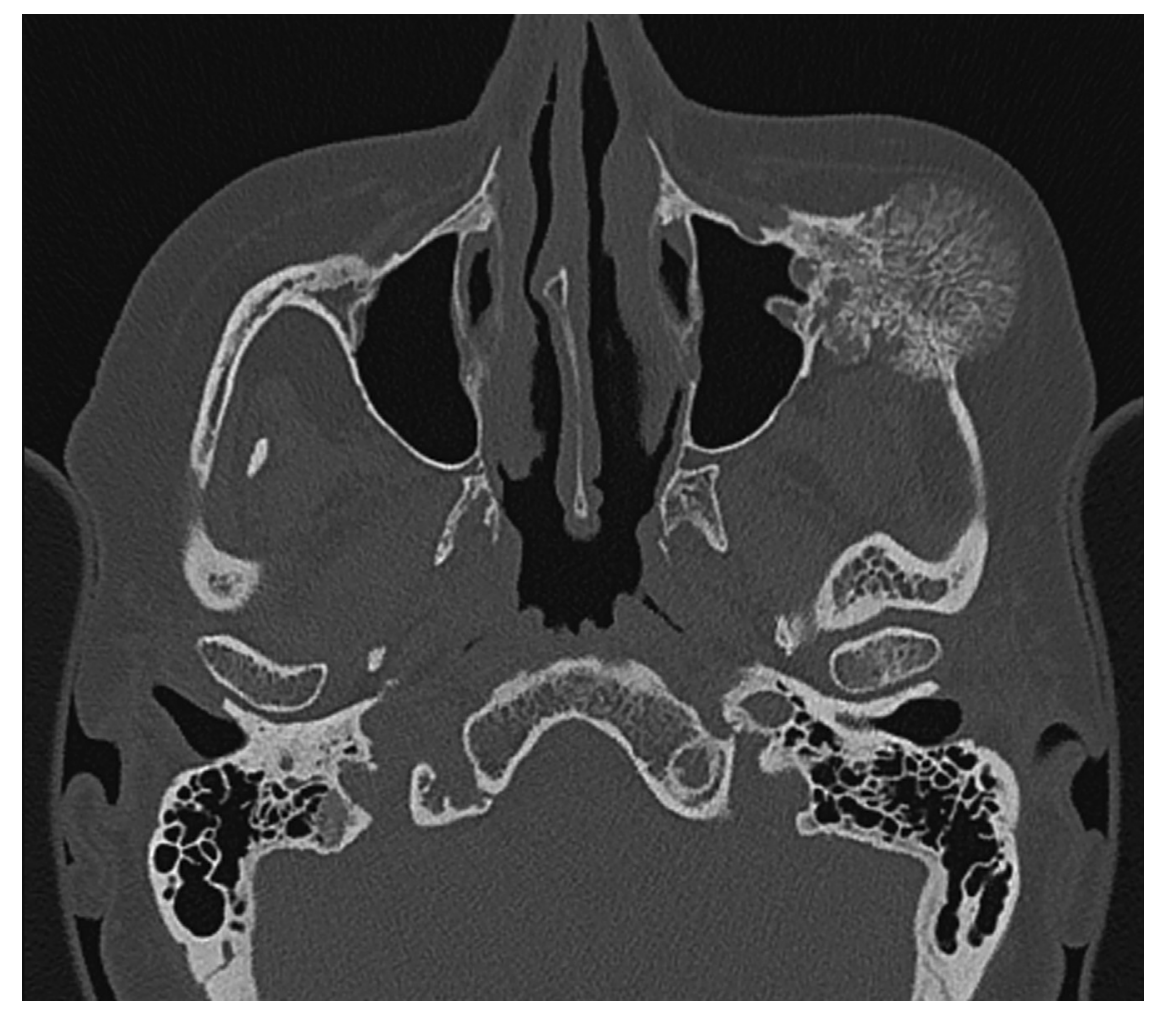

FIGURE 17. Axial view of preoperative computed tomography scan of 58-year-old woman with orbito-zygomatic osseous cavernous hemangioma. Nicot et al. Orbito-Zygomatic Complex Reconstruction. J Oral Maxillofac Surg 2019. 


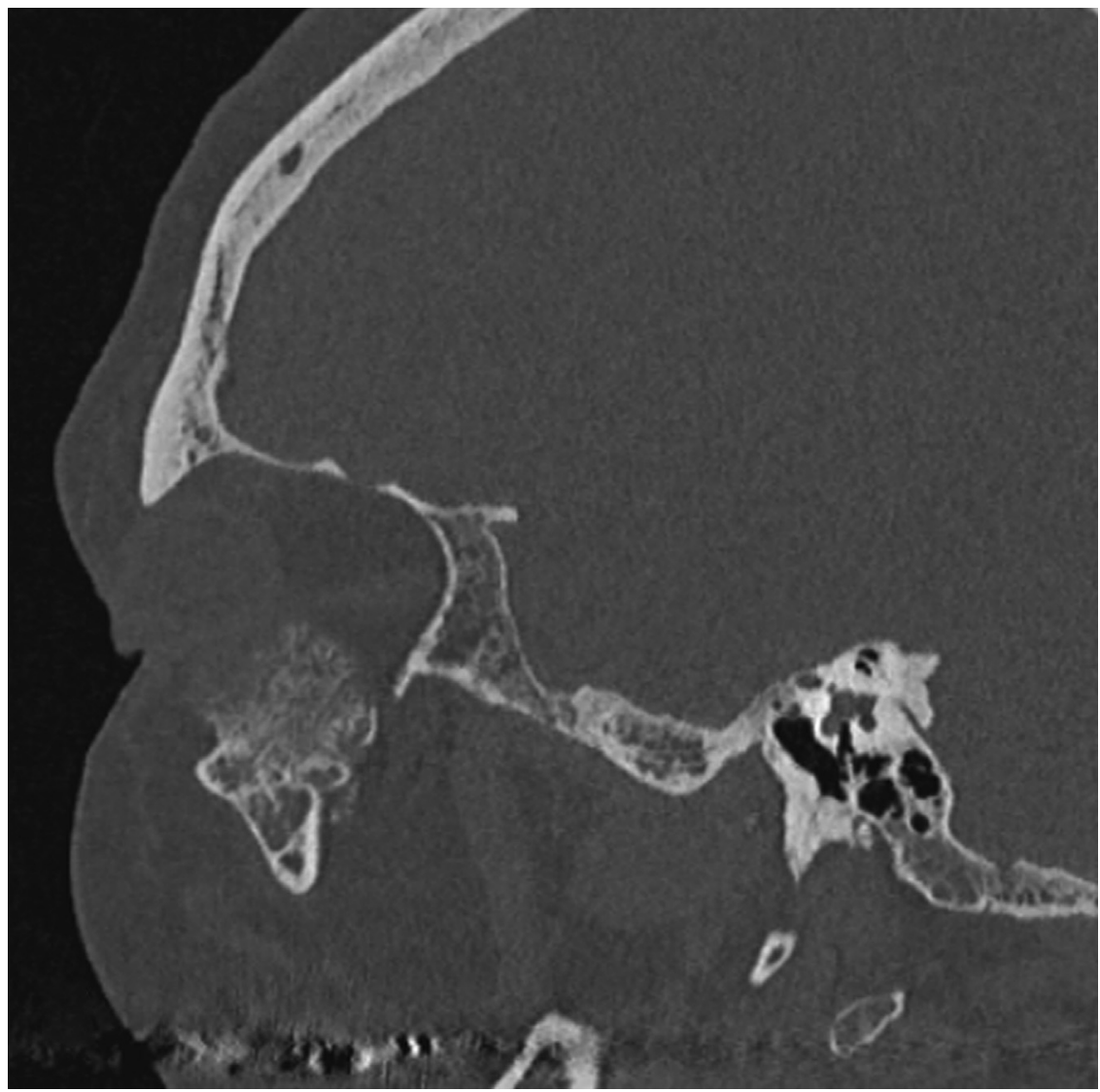

FIGURE 18. Sagittal view of preoperative computed tomography scan of 58-year-old woman with orbito-zygomatic osseous cavernous hemangioma.

Nicot et al. Orbito-Zygomatic Complex Reconstruction. J Oral Maxillofac Surg 2019.

osteoinductive, osteoconductive, and immunocompatible properties. ${ }^{1,2,4,8}$ Several bone-donor sites exist for bone grafts, and each has advantages and disadvantages. ${ }^{4,8}$ We chose to use a nonvascularized calvarial autologous bone graft in reconstruction planning. This choice was justified given the benign nature of resected tumors and the absence of adjuvant radiotherapy. These cortical grafts are mainly osteoconductive, but the surviving osteoblasts provide some osteogenic properties as well. ${ }^{8}$ Calvarial unicortical bone grafts are characterized by the large volume available with low donor-site morbidity. ${ }^{4,9}$ In particular, the level of postoperative pain after harvesting is classically lower with a calvarial graft than with an anterior iliac crest graft. However, shaping the bone plates is very difficult owing to the anatomic complexity of the OZC. ${ }^{2,8}$ The use of CAD-CAM reduces these shaping difficulties, reproducing the original orbito-zygomatic anatomic landmarks and orbital volume with reduced surgical time. ${ }^{1,2,-7,10,11}$ A freehand reconstruction would require multiple adjustments, whereas with CAD-CAM, the assembly is performed in just a few minutes. The possibility of performing the reconstruc- tion in 2 parts, which assemble themselves optimally at the infraorbital rim using preformed titanium miniplates, allows us to realize a more discrete approach. Thus, a subciliary approach, sometimes supplemented by an intraoral approach, was performed in most cases. It is possible to slightly increase the length of the subciliary approach, depending on the size or location of the tumor, by completing the extraoral scar with a paralateronasal approach. The main complications encountered in orbital reconstructive surgery, such as dystopia or anophthalmia, are otherwise limited by precisely maintaining orbital volume. ${ }^{10,11}$ If we focus on the survival of these bone implants, membranous bone grafts, such as calvarial bone grafts, are superior to endochondral bone grafts in terms of the volume maintenance. ${ }^{12}$ On the other hand, bone-free flaps have an advantage of rapid incorporation into the host bone and vascular flow, with higher donor-site morbidity. ${ }^{1,2,8,12}$ Our choice is therefore justified by lower morbidity with biological properties favorable for the long-term survival of bone grafts. For benign tumors, no radiotherapy is to be expected, and the possibility of preserving the underlying periosteum contributes to the survival of 


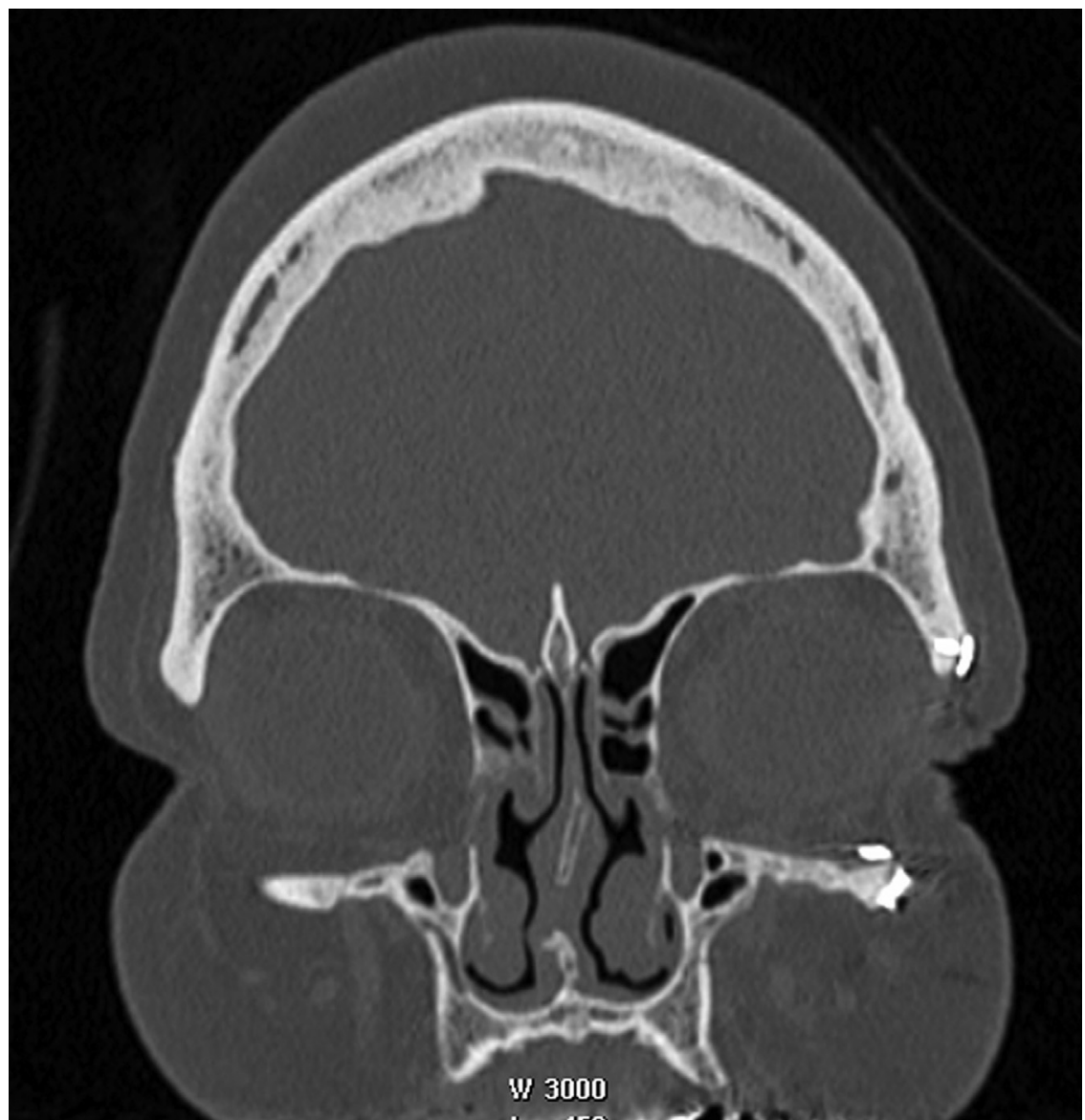

FIGURE 19. Coronal computed tomography scan of 58-year-old woman with orbito-zygomatic osseous cavernous hemangioma 9 months after surgical procedure. The shape of the orbito-zygomatic complex was restored. Bone healing of the calvarial bone fragments with each other and with the rest of the midface can be visualized.

Nicot et al. Orbito-Zygomatic Complex Reconstruction. J Oral Maxillofac Surg 2019.

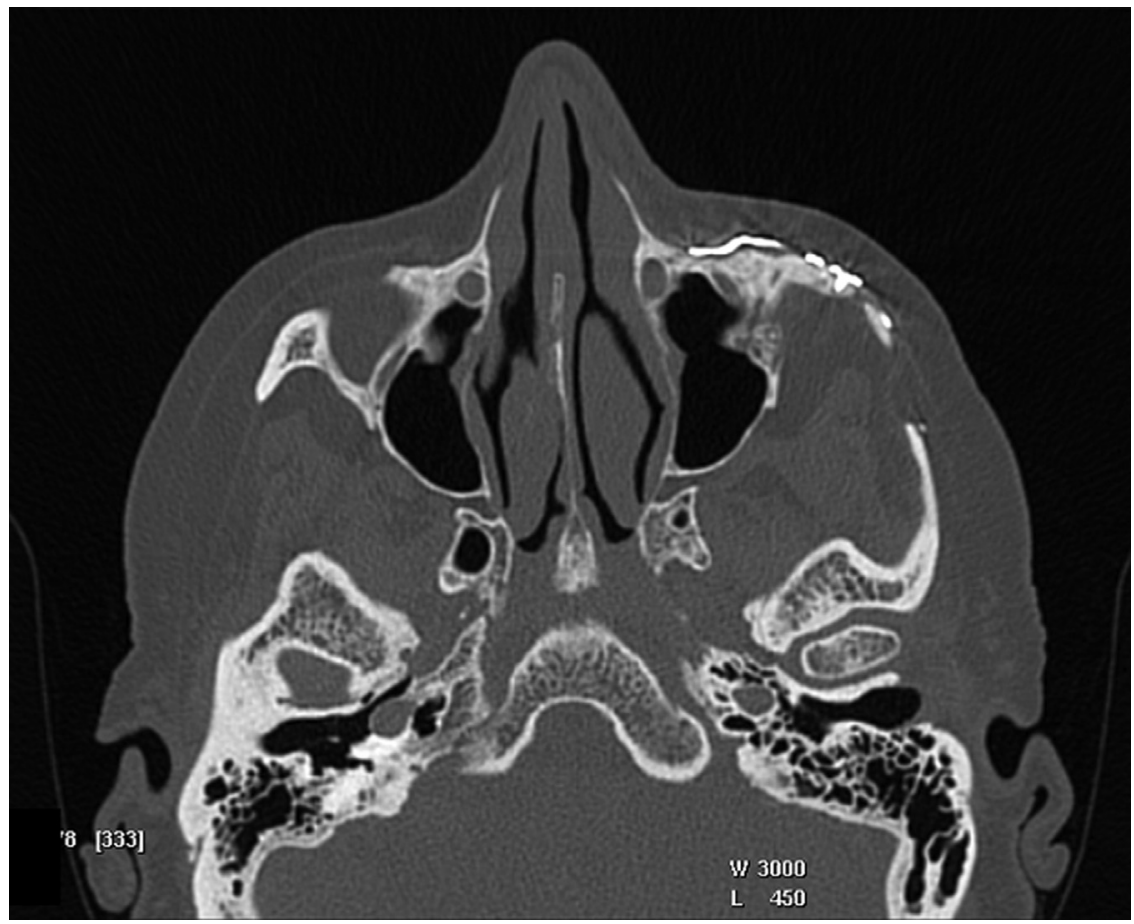

FIGURE 20. Axial computed tomography scan of 58-year-old woman with orbito-zygomatic osseous cavernous hemangioma 9 months after surgical procedure. 


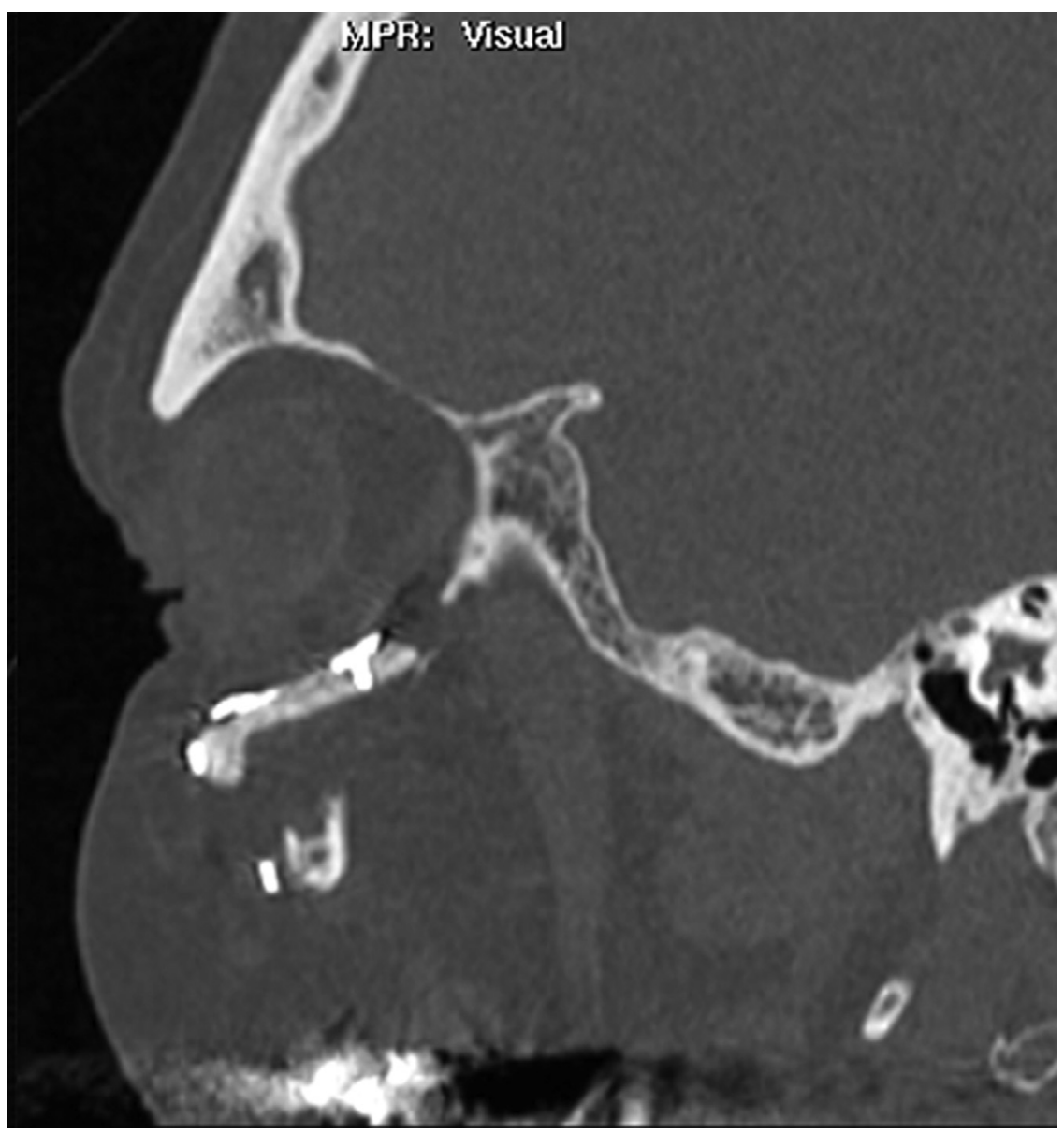

FIGURE 21. Sagittal computed tomography scan of 58-year-old woman with orbito-zygomatic osseous cavernous hemangioma 9 months after surgical procedure.

Nicot et al. Orbito-Zygomatic Complex Reconstruction. J Oral Maxillofac Surg 2019.

these grafts. Finally, 3-dimensional planning and computer-assisted design and manufacturing are growing technologies in the field of facial reconstruction. ${ }^{13,14}$ They allow for increased efficiency and accuracy during bone reconstructive surgery, especially in a complex anatomic area, owing to the form and the maintenance of related structures. ${ }^{13}$

\section{Acknowledgments}

We thank Camille Ribolzi, Florian Langlois, and Jeremy Hagen, engineers at Materialise (Châtillon, France), for their contribution to the design and manufacturing of the described devices.

\section{References}

1. Cordeiro PG, Chen CM: A 15-year review of midface reconstruction after total and subtotal maxillectomy: Part II. Technical modifications to maximize aesthetic and functional outcomes. Plast Reconstr Surg 129:139, 2012

2. Moskowitz BK, Patel AD, Pearson JM: Aesthetic and functional management of eyelid and orbital reconstruction. Facial Plast Surg 24:69, 2008
3. Baino F: Biomaterials and implants for orbital floor repair. Acta Biomater $7: 3248,2011$

4. Tessier P, Kawamoto H, Posnick J, et al: Complications of harvesting autogenous bone grafts: A group experience of 20,000 cases. Plast Reconstr Surg 116:72S, 2005

5. Vehmeijer M, van Eijnatten M, Liberton N, Wolff J: A novel method of orbital floor reconstruction using virtual planning. J Oral Maxillofac Surg 74:1608, 2016

6. Baumann A, Sinko K, Dorner G: Late reconstruction of the orbit with patient-specific implants using computer-aided planning and navigation. J Oral Maxillofac Surg 73:S101, 2015

7. Schouman T, Khonsari RH, Goudot P: Shaping the fibula without fumbling: The SynpliciTi customised guide-plate. Br J Oral Maxillofac Surg 53:472, 2015

8. Zimmermann G, Moghaddam A: Allograft bone matrix versus synthetic bone graft substitutes. Injury 42(Suppl 2):S16, 2011

9. Touzet S, Ferri J, Wojcik T, Raoul G: Complications of calvarial bone harvesting for maxillofacial reconstructions. J Craniofac Surg 22:178, 2011

10. Day KM, Gabrick KS, Sargent LA: Applications of computer technology in complex craniofacial reconstruction. Plast Reconstr Surg Glob Open 6:e1655, 2018

11. Huang L, Lin L, Wang Z, et al: Personalized reconstruction of traumatic orbital defects based on precise three-dimensional 
orientation and measurements of the globe. J Craniofac Surg 28 172,2017

12. Zins JE, Whitaker LA: Membranous versus endochondral bone: Implications for craniofacial reconstruction. Plast Reconstr Surg 72:778, 1983
13. Pfaff MJ, Steinbacher DM: Plastic surgery applications using three-dimensional planning and computer-assisted design and manufacturing. Plast Reconstr Surg 137:603e, 2016

14. Largo RD, Garvey PB: Updates in head and neck reconstruction. Plast Reconstr Surg 141:271e, 2018 